\title{
Investigating the Role of Foreign Language Anxiety in Explicit and Implicit L2 Knowledge
}

\author{
Runhan Zhang ${ }^{1}$ \\ ${ }^{1}$ School of Foreign Studies, Central University of Finance and Economics, Beijing, China \\ Correspondence: Runhan Zhang, School of Foreign Studies, Central University of Finance and Economics, \\ Beijing, China. E-mail: runhanzhang@cufe.edu.cn
}

Received: August 12, 2019

Accepted: September 12, 2019 Online Published: November 12, 2019

doi:10.5539/ijel.v9n6p365

URL: https://doi.org/10.5539/ijel.v9n6p365

\begin{abstract}
Empirical studies have provided evidence for the negative role of foreign language anxiety in language proficiency measured via final course grades, self-assessments, objective language tests, and GPAs. However, its role in language proficiency from the perspective of explicit and implicit L2 knowledge is under-investigated. The current study therefore investigates the relationship between foreign language anxiety and explicit and implicit L2 knowledge in an English as a foreign language context. Participants were 156 university-level non-English majors. The results of the $t$ test and multiple regression analyses showed that foreign language anxiety has a negative role in implicit L2 knowledge and also can predict it, but it was not found to have a significantly negative role in explicit L2 knowledge. The nature of the tests and knowledge may account for the results.
\end{abstract}

Keywords: foreign language anxiety, explicit L2 knowledge, implicit L2 knowledge, correlation

\section{Introduction}

Anxiety is a topic that has attracted the attention of several researchers in the field of second language acquisition (SLA) (Kim, 2000). It is defined as "the subjective feeling of tension, apprehension, nervousness, and worry associated with an arousal of the autonomic nervous system" (Spielberger, 1983, p. 1), a feeling that has been traditionally treated as trait, state, or situation-specific anxiety. However, SLA researchers have increasingly adopted a situation-specific definition of anxiety that differs from more general types. Horwitz, Horwitz, and Cope (1986) proposed the so-called foreign language classroom anxiety (FLCA) construct and conceptualized it as a "distinct complex of self-perceptions, beliefs, feelings, and behaviors related to classroom language learning arising from the uniqueness of the language learning process" (p. 128). Following this definition, they introduced the Foreign Language Classroom Anxiety Scale (FLCAS), which is by far the most widely used questionnaire and has resulted in more stable empirical findings and an overall more systemic investigation of anxiety in SLA.

Foreign language anxiety is considered one of the predictors of L2 attainment in SLA (MacIntyre \& Gardner, 1991), because it "poses several potential problems for the student of a foreign language" and "it can interfere with the acquisition, retention and production of the new language" (MacIntyre \& Gardner, 1991, p. 86). Several studies have also provided evidence for its negative role in language proficiency, which can be measured through final course grades, self-assessments, objective language tests, and GPAs (e.g., Aida, 1994; Chasten, 1975; Horwitz, 2017; MacIntyre, 2017). However, very few studies have focused on the relationship between foreign language anxiety and language proficiency from the perspective of explicit and implicit L2 knowledge.

Therefore, this study investigates the relationship between foreign language anxiety in first-year non-English majors and explicit/implicit L2 knowledge in an English as a foreign language (EFL) context. The following two research questions guided the study:

1) To what extent do first-year non-English majors have explicit and implicit L2 knowledge?

2) What is the relationship between foreign language anxiety and explicit/implicit L2 knowledge?

\section{Review of Studies on Foreign Language Anxiety and Explicit/Implicit L2 Knowledge}

As mentioned earlier, very few studies have focused directly on the relationship between foreign language 
anxiety and explicit/implicit L2 knowledge. However, the findings of several studies using the Foreign Language Classroom Anxiety Scale (FLCAS) have demonstrated that foreign language anxiety is more likely to correlate negatively with scores derived from speaking and time-pressured tasks, in which learners are more likely to draw on their implicit L2 knowledge. Several other studies have also suggested that there may be a negative relationship between foreign language anxiety and explicit L2 knowledge (Argaman \& Abu-Rabia, 2002; Wu, 2011).

Phillips (1992), for example, examined the effects of students' anxiety on performance on an oral French test. Participants were 44 students enrolled in two-third semester French classes at Southwestern University in the United States. Their oral proficiency was examined in two ways: (1) free talk on a given cultural topic randomly selected from readings of two chapters (e.g., "Pourriez-vous me parler un peu de la France? La geographie? La agriculture? L'industrie?"); and (2) role play. Students were given a randomly assigned cue sheet with directions in English providing the framework for a situation (e.g., "You will play the role of an older brother/sister. Ask your sister about her French class"). Each situation was designed to elicit a target structure studied in the chapters (e.g., passé composé). The students' oral production was audio-recorded. Pearson correlations were computed to investigate the relationship between participants' FLCAS scores and their oral exam grades. A moderate negative correlation was found between the scores on these two measures $(r=0.40, p<.01)$, suggesting that there is a relationship between language anxiety and implicit knowledge, since the oral proficiency measures (free talk and role play) used in this study were likely to have involved the students' online processing.

Cheng (2002) examined the relationship between language anxiety and language proficiency in Taiwanese college learners of English in Southern Taiwan and found that oral-oriented activities were the most foreign language anxiety-provoking activities in the foreign language classroom. Yan and Horwitz (2008) reported that some language learners believe that language anxiety can affect their speaking performance in a language class and thus make them feel frustrated, incapable, and even angry. For example, one language learner who suffered from high communication anxiety reported the following: "it seems that I had this kind of feeling (anxiety) before- that is, in class when the teacher suddenly asked you (to speak) ...” (Yan \& Horwitz, 2008, p. 160). According to Horwitz, Horwitz and Cope (1986), language highly anxious learners are afraid to speak in the foreign language classroom and "feel a deep self-consciousness when asked to risk revealing themselves by speaking the foreign language" (p. 129) in front of the class. In contrast to speaking and listening, reading and writing are less affected by anxiety in the foreign language classroom (Kim, 2000). According to MacIntyre, Noels and Clement (1997), it can be embarrassing to interrupt a conversation if learners do not understand what other people are saying; however, reading "allows for repetition and clarification with minimal risk of embarrassment" (pp. 279-280) since it is quite private and individual. As Ellis (2008) observed, "when anxiety does arise relating to the use of the L2, it seems to be restricted mainly to speaking and listening, reflecting learners' apprehension at having to communicate spontaneously in the L2" (p. 692). It can be also inferred that there is more likely to be a negative relationship between language anxiety and implicit knowledge, since learners tend to draw on their implicit knowledge in listening and speaking, where online processing and intuitive awareness are implicated. Accordingly, a negative correlation between language anxiety and implicit knowledge is expected in this study.

Conversely, Argaman and Abu-Rabia (2002) reported that foreign language anxiety has also been found to have a negative relationship with reading and writing tasks, probably suggesting a relationship between foreign language anxiety and explicit L2 knowledge. Generally, although reading and writing tasks do not require spontaneous learners' response, they require careful thinking compared to listening and speaking tasks. Thus, these two tasks may result in learners' engaging in offline processing and access to their explicit knowledge. In the meanwhile, students in the study by Argaman and Abu-Rabia (2002) were required to pay attention to grammatical accuracy in the writing task, so they may again have accessed their explicit knowledge.

$\mathrm{Wu}$ (2011) also identified a general trend of less foreign language anxiety in relation to higher reading performance in 91 first-year college students at a private university in Southern Taiwan who were studying English as a foreign language. Their reading comprehension was measured by two multiple-choice reading comprehension tests. Each test consisted of a dialogue passage of around 300 words extracted from the textbook used in the reading classes. In each test, participants were required to answer 20 multiple-choice questions based on the passage within 30 minutes. Their scores on the two tests were averaged to provide a general measure of reading comprehension. $\mathrm{Wu}(2011)$ found a negative relationship between language anxiety and reading scores (i.e., students with low anxiety achieved higher comprehension scores).

Considered together, these previous studies suggest a negative relationship between foreign language anxiety and 
both implicit and explicit L2 knowledge, but possibly a stronger relationship with implicit L2 knowledge. Therefore, this study hypothesizes that there is a negative relationship between foreign language anxiety and both explicit and implicit L2 knowledge.

\section{Method}

\subsection{Participants and Context}

This study was conducted at a major university in Beijing, mainland China. Participants were 156 first-year non-English majors who were majoring in economics, business, and management. All students were in the latter half of their first year. Most participants were women. Their ages ranged from 17 to 19 years. In addition, they were assured that the information collected would not affect their course grades. No one was forced to participate, and all participants signed a consent form and were assured of their right to withdraw their participation at any time. Data collection took place outside of class time and regular classes were not interrupted. Four language labs (of around 40 seats each) of the university were used to administer the computer-delivered and paper-and-pencil tests and questionnaires.

\subsection{Materials and Instruments}

\subsubsection{Target Structures}

This study investigated the same 17 grammatical structures used in Ellis $(2005,2009)$. The choice of the grammatical structures proposed by Ellis $(2005,2009)$ was based on several considerations, including universally problematic grammatical structures, developmental properties, different levels of instruction, and grammatical type (see Ellis, 2008; Zhang, 2015). Table 1 below shows two examples of embedded questions and plural-s.

Table 1. Grammatical structures

\begin{tabular}{lllll}
\hline Structure & Example of Learner Error & Acquisition & Pedagogical Introduction & Type \\
\hline Embedded questions & Tom wanted to know what had I done. & Late & Senior high school & Syntactical \\
Plural-s & Martin sold some old coins to a shop. & Early & Various levels & Morphological \\
\hline
\end{tabular}

\subsubsection{Explicit and Implicit L2 Knowledge Tests}

This study used four tests to examine participants' explicit and implicit L2 knowledge, namely the elicited oral imitation test (EIT), the timed grammaticality judgment test (TGJT), the untimed grammaticality judgment test ungrammatical items (UGJT UG), and the metalinguistic knowledge test (MKT).

\subsubsection{Elicited Oral Imitation Test (EIT)}

This test consists of 34 belief statements (one grammatical and one ungrammatical sentence per structure). The sentences were presented orally to participants through a computer. Participants were first required to indicate their choice on paper, as well as to express whether they agreed with, disagreed with, or were not sure about the truth value of each statement. Examples of belief statements for comparatives are as follows:

- Chinese people are more pleasant and polite than other people. (Grammatical)

- Learning math is harder than learning chemistry. (Ungrammatical)

The test was intended to first attract learners' attention to meaning. Participants were then asked to repeat the sentences orally in correct English and their responses were audio-recorded. The obligatory occasion analysis was adopted to analyze their use of the target structures. If participants failed to imitate a sentence at all or to reproduce it in a way that they did not create an obligatory context for its target structure, they would receive a score of 0 . A score of 1 was allocated if the target structure was correctly provided. Scores were expressed as correct percentage.

\subsubsection{Timed Grammaticality Judgment Test (TGJT)}

This is a computer-delivered test consisting of 68 sentences, evenly divided between grammatical and ungrammatical. The sentences, which are different from those in the imitation test, were presented in written form on the computer screen. Thus, there were four sentences to be judged for each of the 17 grammatical structures. Examples of sentences for the auxiliary verb "do" are as follows:

- Did Martin visited his father yesterday? (Ungrammatical)

- Did Keiko completed her homework? (Ungrammatical) 
- Did Cathy cook dinner last night? (Grammatical)

- Does Keum live in Auckland? (Grammatical)

There was a fixed time limit and participants needed to indicate whether each sentence was grammatical or ungrammatical by pressing response buttons. The time allowed for judging the individual sentences ranged from 1.8 to 6.24 seconds. Each item was scored dichotomously as correct/incorrect, and items that were not answered at all scored incorrect. A percentage accuracy score was calculated. Participants' scores for the entire test, as well as separate scores for the grammatical and ungrammatical items, were also calculated.

\subsubsection{Untimed Grammaticality Judgment Tests (UGJT)}

This paper-based test has the same content as the TGJT. The sentences were presented in written form. This test provided three separate measures: an overall percentage judgment accuracy score based on participants' dichotomous responses and separate scores for the grammatical/ungrammatical items, a percentage certainty score, and a percentage score based on participants' reported use of "rule" in judging each item. In this study, only the scores for the ungrammatical items were collected for analysis (See Zhang, 2015).

\subsubsection{Metalinguistic Knowledge Test (MKT)}

This is an adaptation of an earlier metalanguage test devised by Alderson, Clapham and Steel (1997). It consists of a two-part untimed computerized multiple-choice test. Part 1 presented participants with 17 ungrammatical sentences based on the 17 structures. Participants were required to select the rule that best explained each error out of four choices provided, as in this example:

- Martin work in a car factory.

a. Work is a noun, so it cannot have the subject "Martin".

b. We must use the present simple tense after pronouns.

c. We need an "s" after the verb to indicate third person plural.

d. In the third person singular the present tense verb takes "s".

Part 2 comprised two sections. In Section 1, students were asked to identify the corresponding item for each grammatical feature of a given passage. For example, "the" was the corresponding item for the grammatical feature "definite article". Section 2 contained four sentences. Participants needed to find the item corresponding to the grammatical feature in each sentence, as in this example:

- Joe had nowhere to stay. (Infinitive)

Participants' scores for the entire test were collected.

\subsubsection{Foreign Language Classroom Anxiety (FLCAS)}

Horwitz, Horwitz and Cope's FLCAS was employed to investigate participants' foreign language anxiety. This scale has been administered in several separate studies, and its validity as a measure of language anxiety has been established. It consists of 33 items aiming to investigate students' language anxiety from three aspects: (1) communication apprehension, (2) test anxiety, and (3) fear of negative evaluation (Horwitz, 1991, p. 30). Among them, 15 items relate to communication apprehension because "the construct of communication apprehension is quite relevant to the conceptualization of foreign language anxiety" (McCroskey, 1970, as cited in Horwitz, 1991, p. 30). As demonstrated by Horwitz (1991), characteristics such as "difficulty in speaking in groups or in public" or difficulty "in listening to or learning a spoken message" are "manifestations of communication apprehension" (p. 30). Further, test anxiety, as its name implies, refers to the "apprehension over academic evaluation" (MacIntyre \& Gardner, 1991, as cited in Horwitz, 1991, p. 42). Three items $(8,10$, and 21) relate to test anxiety. Finally, 14 items examine fear of negative evaluation. Participants were required to choose from responses 1 to 5 to indicate the extent to which they agreed or disagreed with a statement. The total score of the entire scale was 165. A percentage score was calculated.

\subsection{Data Collection}

All participants first gathered in two classrooms and were required to finish the FLCAS one week after the beginning of the new term. The next day, all participants were gathered and divided into different groups, with three participants in each group. The EIT was administered group by group. For example, three students in first group took the test simultaneously in the same room. They sat quite far from each other in order not to disturb each other. After they finished the test, the second group came in to take the test. In the test, explanation and the training session were given first to ensure each student understood what to do. Then s/he began the test. Each 
student's imitations were recorded using the recording system on the computer. Each session lasted around 20 minutes. Around 10 days were used to administer this test. The whole test lasted around 10 days. Then, participants were gathered again and sent to four different rooms to finish the TGJT, but without a time limit. The participants first finished the examples and then began the test. All three tests were completed in a single session lasting approximately two and a half hours.

\section{Results}

\subsection{Reliability of the Tests and the FLCAS}

A series of statistical analyses was conducted to investigate the reliability of the tests and the FLCAS in the current sample. Table 2 shows the reliability coefficient for each of the four tests, as well as the FLCAS. According to DeVellis (1991), Cronbach's alpha values ranging from .65 to .70 indicate acceptable reliability, whereas values from .70 to .80 indicate fairly good reliability and thus very good consistency. As seen in Table 2, all alphas for the tests and the FLCAS indicate high reliability for the current learner population $(>.80)$.

Table 2. Reliability values of the tests and the FLCAS $(n=156)$

\begin{tabular}{ll}
\hline Test & Reliability $(\boldsymbol{\alpha})$ \\
\hline EIT & .83 \\
TGJT & .84 \\
UGJT UG & .85 \\
MKT & .80 \\
FLCAS & .87 \\
\hline
\end{tabular}

Note. EIT = Elicited Oral Imitation Test; TGJT = Timed Grammaticality Judgment Test; UGJT UG = Untimed Grammaticality Judgment Test, ungrammatical items; MKT $=$ Metalinguistic Knowledge Test; FLCAS $=$ Foreign Language Classroom Anxiety Scale.

Regarding the first research question on the extent to which first-year non-English majors have explicit and implicit L2 knowledge, descriptive statistics are summarized in Table 3, which shows the means and standard deviations of scores on the four tests. It can be seen that participants scored higher on the TGJT $(M=.60)$ than on the EIT $(\mathrm{M}=.47)$.

Table 3. Descriptive statistics of the tests and the FLCAS $(n=156)$

\begin{tabular}{llll}
\hline Tests & Items & Mean & SD \\
\hline EIT & 34 & .47 & .15 \\
TGJT & 68 & .60 & .16 \\
UGJT UG & 34 & .89 & .10 \\
MKT & 40 & .61 & .17 \\
FLCAS & 33 & .55 & .09 \\
\hline
\end{tabular}

Note. EIT $=$ Elicited Oral Imitation Test; TGJT $=$ Timed Grammaticality Judgment Test; UGJT = Untimed Grammaticality Judgment Test, ungrammatical items; MKT $=$ Metalinguistic Knowledge Test; FLCAS $=$ Foreign Language Classroom Anxiety Scale.

Subsequently, four paired-samples t-tests were conducted to investigate whether participants' scores on the measures of implicit L2 knowledge were significantly different from their scores on those of explicit L2 knowledge. The results are shown in Table 4 below and indicate that there was a significant difference between participants' implicit and explicit knowledge of English.

Table 4. Paired-sample $t$ test of first-year students' scores on measures of implicit and explicit L2 knowledge (n $=156)$

\begin{tabular}{lllllll}
\hline & \multicolumn{5}{l}{ UGJT UG } & MKT \\
\cline { 2 - 7 } & SEM & $t$ & Sig. (2-tailed) & SEM & $t$ & Sig. (2-tailed) \\
\hline EIT & .03 & -27.66 & .000 & .02 & -31.38 & .000 \\
TGJT & .03 & -11.95 & .000 & .02 & -6.75 & .000
\end{tabular}

Note. EIT $=$ Elicited Oral Imitation Test; TGJT $=$ Timed Grammaticality Judgment Test; UGJT = Untimed Grammaticality Judgment Test, ungrammatical items; MKT = Metalinguistic Knowledge Test; FLCAS = Foreign Language Classroom Anxiety Scale.

4.2 Correlation Between Foreign Language Anxiety and Explicit/Implicit L2 Knowledge

To answer the second research question, a Pearson Product correlation analysis and multiple regression analyses 
were carried out to explore the relationship between participants' foreign language anxiety and explicit/implicit L2 knowledge. Tables 5 and $6(a-b)$ show the results of the correlation and multiple regression analyses, respectively. Foreign language anxiety was found to have a significant and moderate negative relationship with the EIT $(r=-.337)$. It was also found to correlate significantly with the TGJT $(r=-.199)$, but it did not have a significant relationship with either the UGJT UG or the MKT.

From Table $6(\mathrm{a}-\mathrm{b})$, it can be seen that foreign language anxiety significantly predicted the EIT scores $(\mathrm{F}=10.925$, $\mathrm{p}=0.001<0.05)$ and the TGJT scores $(\mathrm{F}=7.972, \mathrm{p}=.047<.05)$. The results revealed that, in this sample of first-year non-English majors, students with higher foreign language anxiety tended to have less implicit knowledge than those with lower foreign language anxiety. However, it should be noted that foreign language anxiety only accounted for $9.1 \%$ and $3 \%$ of the variance in the EIT and TGJT, respectively. As mentioned in a previous study, the "beta value is a measure of how strongly each predictor variable influences the dependent variable" and "the higher the beta value the greater the impact of the predictor variable on the dependent variable" (Brace, Kemp, \& Snelgar, 2006, p. 208). Thus, language anxiety was found to be the best predictor of the EIT, with a beta of .337 .

Table 5. Correlations between foreign language anxiety and explicit/implicit L2 knowledge

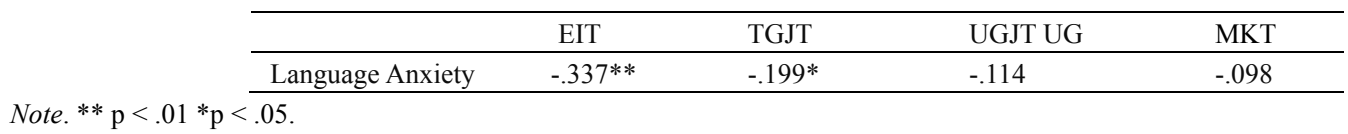

Table 6a. Multiple regression of foreign language anxiety to the EIT

\begin{tabular}{llll}
\hline Model & Beta & T & Sig. (p) \\
\hline Language Anxiety & -.337 & -3.305 & .001 \\
$\mathrm{R}=.337$ & $\mathrm{R}^{2}=.100$ & Adjusted $\mathrm{R}^{2}=.091$ & $\mathrm{~F}=10.925$ \\
\hline
\end{tabular}

Table $6 \mathrm{~b}$. Multiple regression of foreign language anxiety to TGJT

\begin{tabular}{llll}
\hline Model & Beta & T & Sig. (p) \\
\hline Learner Beliefs & -.199 & -2.010 & .047 \\
$\mathrm{R}=.199$ & $\mathrm{R}^{2}=.040$ & Adjusted $\mathrm{R}^{2}=.030$ & $\mathrm{~F}=7.972$ \\
\hline
\end{tabular}

\section{Discussion and Implications}

This study mainly investigated the extent to which Chinese non-English majors have explicit and implicit L2 knowledge, as well as whether foreign language anxiety plays a role in the two types of knowledge. The results suggest a significant difference between participants' implicit and explicit knowledge of English. Participants obtained much higher scores on both explicit knowledge measures than on the two implicit knowledge measures (as shown in Table 3). In other words, the first-year non-English majors in this study seemed to have much greater explicit knowledge than implicit knowledge of English, as anticipated. The English instruction that this group of learners had received may account for the result. Prior to entering university, the instruction they received was mainly form-focused and exam-directed. Thus, they were likely to have primarily developed explicit knowledge of English.

In terms of whether foreign language anxiety plays a role in the two types of knowledge, the results show that foreign language anxiety correlated negatively and predicted the scores of implicit knowledge measures, as hypothesized. However, contrary to the results of Argaman and Abu-Rabia (2002) and Wu (2011), it was not found to correlate with the scores of explicit knowledge measures. Such results are probably due to the time pressure involved in the two measures of implicit L2 knowledge and the nature of the explicit L2 knowledge measures. The EIT comprises listening and speaking, which means that L2 learners need to decode an interlocutor's message instantly within a very short period. The TGJT also requires learners to judge whether each statement is grammatical or ungrammatical within a short time. Therefore, the time pressure which may need learners' online processing may increase participants' level of anxiety and consequently drain their attentional resources (Teimouri, Goetze, \& Plonsky, 2019). However, the two measures of explicit L2 knowledge are unlike the those of implicit L2 knowledge. In the two explicit knowledge measures, students can read and judge all items at their own pace. They may be allowed to re-read and re-judge the parts they do not fully understand and are not completely sure about, and to use other resources to aid their comprehension and 
judgment. The findings of the present study provide empirical evidence for the negative relationship between foreign language anxiety and implicit L2 knowledge, which is the ultimate goal of L2 acquisition (Doughty, 2003), indicating that students who lack implicit knowledge may be more anxious in high time-pressured tasks. Such findings also support the evolution of anxiety research from a trait-like variable to a more situation-specific construct targeting different language-skills.

Foreign language anxiety, however, is obviously not the only factor affecting the development of implicit L2 knowledge, as indicated in the result that foreign language anxiety only accounted for $9.1 \%$ and $3 \%$ of the variance in the EIT and TGJT, respectively. However, from a psychological perspective, the study of anxiety is important because students' beliefs can affect their attitudes toward language class, even language learning. The results of the current study have important implications for language teachers, practitioners, and learners, given that knowing the role of foreign language anxiety in implicit L2 knowledge may arouse their attention to anxiety, encouraging them to use several techniques to lower learners' level of foreign language anxiety and thus enhance their implicit L2 knowledge. For example, Oxford et al. (1989) observed that metacognitive strategies may be helpful for learners to reduce their anxiety. Such strategies help them consciously plan, self-evaluate, and self-monitor their progress. Foss and Reitzel (1988) contend that discussing their fears about language learning indicates to students that they are not alone in their anxiety, and that the instructor understands their apprehension; moreover, the discussion itself encourages learners to relax. Instructors should begin the semester by confronting the issue of foreign language classroom anxiety directly. Phillips (1991) suggested that several techniques can be initiated by teachers to provide learners with a more pleasant classroom experience to reduce their foreign language anxiety, such as modeling (rephrasing students' comments in the appropriate form), teaching conversation strategies, and cooperative learning activities. As mentioned earlier, foreign language anxiety is not the only factor that can affect the development of implicit L2 knowledge. Future studies should include more individual difference factors in order to obtain a clearer picture of the factors that may influence the development of implicit and explicit L2 knowledge

\section{References}

Aida, Y. (1994). Examination of Horwitz, Horwitz, and Cope's construct of foreign language anxiety: The case of students of Japanese. Modern Language Journal, 78(2), 155-168. https://doi.org/10.1111/j.1540-4781.1994.tb02026.x

Alderson, J. C., Steel, D., \& Clapham, C. (1997). Metalinguistic knowledge, language aptitude and language proficiency. Language Teaching Research, 1(2), 93-121. https://doi.org/10.1177/136216889700100202

Argaman, O., \& Abu-Rabia, S. (2002). The influence of language anxiety on English reading and writing tasks among native Hebrew speakers. Language, Culture and Curriculum, 15(2), 143-160. https://doi.org/10.1080/07908310208666640

Brace, N., Kemp, R., \& Sneglar, R. (2006). SPSS for psychologists. London: Psychology Press.

Chasten, K. (1975). Affective and ability factors in second language acquisition. Language Learning, 25(1), 153-161. https://doi.org/10.1111/j.1467-1770.1975.tb00115.x

Cheng, Y. S. (2002). Factors associated with foreign language writing anxiety. Foreign Language Annals, 35(6), 647-656. https://doi.org/10.1111/j.1944-9720.2002.tb01903.x

DeVellis, R. F. (1991). Scale development: Theory and applications. Newbury Park, NJ: Sage Publications.

Doughty, C. (2003). Instructed SLA: Constraints, compensation, and enhancement. In C. Doughty \& M. H. Long (Eds.), The handbook of second language acquisition (pp. 256-310). Malden, MA: Blackwell. https://doi.org/10.1002/9780470756492.ch10

Ellis, R. (2005). Measuring implicit and explicit knowledge of a second language: psychometric study. Studies in Second Language Acquisition, 27(2), 141-172. https://doi.org/10.1017/S0272263105050096

Ellis, R. (2006). Modelling difficulty and second language proficiency: The differential contributions of implicit and explicit knowledge. Applied Linguistics, 27(3), 431-463. https://doi.org/10.1093/applin/aml022

Ellis, R. (2008). The study of second language acquisition (2nd ed.). Oxford: Oxford University Press.

Ellis, R. (2009). Measuring implicit and explicit knowledge of a second language. In Ellis et al. (Eds.), Implicit and explicit knowledge in second language learning, testing and teaching (pp. 65-93). Bristol, Buffalo, and Toronto: Multilingual Matters. https://doi.org/10.21832/9781847691767-004

Foss, K. A., \& Reitzel, A. C. (1988). A relational model for managing second language anxiety. TESOL 
Quarterly, 22(3), 437-454. https://doi.org/10.2307/3587288

Horwitz, E. K. (1991). Preliminary evidence for the reliability and validity of a foreign language anxiety scale. In E. K. Horwitz \& D. J. Young (Eds.), Language anxiety: From theory and research to classroom implications (pp. 37-39). Englewood Cliffs, New Jersey: Prentice Hall.

Horwitz, E. K. (2017). On the misreading of Horwitz, Horwitz, and Cope (1986) and the need to balance anxiety research and the experiences of anxious language learners. In C. Gkonou, M. Daubney, \& J. M. Dewaele (Eds.), New insights into language anxiety: Theory, research and educational implications (pp. 31-50). Bristol, UK: Multilingual Matters. https://doi.org/10.21832/9781783097722-004

Horwitz, E. K., Horwitz, M. B., \& Cope, J. (1986). Foreign language classroom anxiety. Modern Language Journal, 70(2), 125-132. https://doi.org/10.1111/j.1540-4781.1986.tb05256.x

Kim, J. (2000). Foreign language listening anxiety: A study of Korean students learning English. Austin: University of Texas.

MacIntyre, P. D. (2017). An overview of language anxiety research and trends in its development. In C. Gkonou, M. Daubney, \& J. M. Dewaele (Eds.), New insights into language anxiety: Theory, research and educational implications. Bristol, UK: Multilingual Matters. https://doi.org/10.21832/9781783097722-003

MacIntyre, P. D., \& Gardner, R. C. (1991). Methods and results in the study of anxiety and language learning: A review of the literature. Language Learning, 41(1), 85-117. https://doi.org/10.1111/j.1467-1770.1991.tb00677.x

MacIntyre, P. D., Noels, K. A., \& Clément, R. (1997). Biases in self-ratings of second language proficiency: The role of language anxiety. Language Learning, 47(2), 265-287. https://doi.org/10.1111/0023-8333.81997008

McCroskey, J. C. (1970). Measures of communication-bound anxiety. Speech Monographs, 37(4), 269-277. https://doi.org/10.1080/03637757009375677

Oxford, R. L., \& Nyikos, M. (1989). Variables affecting choice of language learning strategies by university students. Modern Language Journal, 73(3), 291-300. https://doi.org/10.1111/j.1540-4781.1989.tb06367.x

Phillips, E. M. (1992). The effects of language anxiety on students' oral test performance and attitudes. Modern Language Journal, 76(1), 14-26. https://doi.org/10.1111/j.1540-4781.1992.tb02573.x

Phillips, J. K. (1991). Upgrading the target language proficiency levels of foreign language teachers. Washington, DC: ERIC Clearinghouse on Languages and Linguistics.

Sorace, A (1996). The use of acceptability judgments in second language acquisition research. In W. Ritchie \& T. Bhatia (Eds.), Handbook of second language acquisition (pp. 375-409). San Diego, CA: Academic Press. https://doi.org/10.1016/B978-012589042-7/50014-1

Spielberger, C. (1983). Manual for the State-Trait Anxiety Inventory (Form Y). Palo Alto, CA: Consulting Psychologists Press. https://doi.org/10.1037/t06496-000

$\mathrm{Wu}, \mathrm{H}$. (2011). An innovative teaching approach for decreasing anxiety and enhancing performance in L2 reading and writing. Sino-US English Teaching, 8(6), 357-363.

Yan, J. X., \& Howitz, E. K. (2008). Learners' perceptions of how anxiety interacts with personal and instructional factors to influence their achievement in English: A qualitative analysis of EFL learners in China. Language Learning, 58(1), 151-183. https://doi.org/10.1111/j.1467-9922.2007.00437.x

Zhang, R. (2015). Measuring university-level L2 learners' implicit and explicit linguistic knowledge. Studies in Second Language Acquisition, 37(3), 457-486. https://doi.org/10.1017/S0272263114000370

\section{Copyrights}

Copyright for this article is retained by the author, with first publication rights granted to the journal.

This is an open-access article distributed under the terms and conditions of the Creative Commons Attribution license (http://creativecommons.org/licenses/by/4.0/). 